\title{
One-year predictors of smoking initiation and of continued smoking among elementary schoolchildren in multiethnic, low-income, inner-city neighbourhoods
}

\author{
Jennifer O’Loughlin, Gilles Paradis, Lise Renaud, Luis Sanchez Gomez
}

\begin{abstract}
Objective-To identify one-year predictors of smoking initiation among neversmokers, and of continued smoking among ever-smokers.

Design-Two sequential cohorts of grade 4 and 5 children. Data were collected as part of Coeur en sante St Louis du Parc, a nonrandomised controlled trial to evaluate the impact of a school-based heart health promotion programme.

Setting-24 inner-city elementary schools located in multiethnic, low-income neighbourhoods in Montreal.

Subject-1824 schoolchildren aged 9-12 years with baseline and one-year follow-up data.
\end{abstract}

Main outcome measures-Changes in smoking behaviour over a year; the ability of baseline data to predict smoking initiation and continued smoking a year later was investigated in logistic regression analyses.

Results-The prevalence of ever-smoking was $21.1 \%$ at baseline and $30.2 \%$ at one-year follow up. One in six neversmokers initiated smoking; one in three ever-smokers continued smoking. Predictors of initiation included age (odds ratio $(O R)=1.6,95 \%$ confidence interval $(\mathrm{CI})=1.3$ to 2.0$)$, male gender $(\mathrm{OR}=1.5$ $(95 \% \mathrm{CI}=1.1$ to 2.0$))$, friends who smoke $(\mathrm{OR}=2.3(95 \% \mathrm{CI}=1.7$ to 3.3$))$, sibling(s) who smoke $(\mathrm{OR}=1.9(95 \% \mathrm{CI}=1.2$ to $3.1)$ ), father/mother who smokes (OR = $2.2(95 \% \mathrm{CI}=1.6$ to 3.0$))$, and frequent high fat/"junk food" consumption (OR = $1.6(95 \% \mathrm{CI}=1.1$ to 2.1$))$. Age and friends who smoke were also independent predictors of continued smoking in both genders. In addition, in boys, current smokers at baseline were 2.6 times $(95 \%$ $\mathrm{CI}=1.4$ to 5.0 ) more likely to continue smoking than past smokers. In girls, being overweight was associated with continued smoking $(\mathrm{OR}=3.5(95 \% \mathrm{CI}=1.6$ to 7.6$))$. Conclusions-Smoking prevention programmes should address parental and sibling influences on smoking, in addition to refusal skills training. Among girls, weight-related issues may also be important.

(Tobacco Control 1998;7:268-275)

Keywords: children, smoking initiation predictors
Introduction

Although smoking prevalence among North American adolescents declined sharply in the 1970s, the decline slowed significantly in the 1980 s, and appears to have levelled off in the 1990s. ${ }^{12}$ Approximately $24-27 \%$ of Canadians aged 15-19 years are smokers. ${ }^{3}$ In 1993, 45\% of eighth-graders (13-14 years), $56 \%$ of 10 thgraders (15-16 years), and $62 \%$ of 12th-graders (17-18 years) in the United States had tried cigarettes; $8 \%, 14 \%$, and $19 \%$, respectively, smoked daily. ${ }^{4}$ Smoking onset among children and adolescents remains a major public health problem.

The process leading to regular smoking generally progresses through five fairly welldefined stages over two to three years irrespective of the age at which smoking first begins. In the preparatory stage, attitudes and beliefs about the utility of smoking are formed. In the trying stage, the individual smokes the first few cigarettes. In the experiment stage, the individual smokes repeatedly but irregularly. In the regular use stage, the individual smokes at least weekly across a variety of situations and personal interactions. Finally the addiction/ dependent smoker stage is characterised by a physiological need for nicotine. ${ }^{15}$ The process rarely begins before age $11-$ most children smoke their first cigarette between 11 and 15 years of age, although a small proportion wait until their late high school years or later. ${ }^{6}$ About a third to a half of young people who experiment with cigarettes become regular users. ${ }^{12}$

Many authors have advocated early intervention to prevent or delay the onset of smoking, ${ }^{7-10}$ but prevention programmes have generally targeted adolescents rather than younger children. ${ }^{11}$ There is a need for research that examines tobacco use among young children, to identify risk factors at each of the very early stages of onset that are amenable to preventive intervention. ${ }^{21}$ However, to date, few studies have investigated predictors of progress through the early stages of smoking onset in longitudinal study designs. In addition, despite substantial evidence of a higher prevalence of smoking among young people $^{1213}$ and adults ${ }^{14-20}$ of low socioeconomic status, few studies have focused specifically on the patterns of smoking onset in this high-risk group. 


\begin{tabular}{ccccc}
\hline $\begin{array}{c}1992 \\
\text { September }\end{array}$ & $\begin{array}{c}1993 \\
\text { May/June }\end{array}$ & September & $\begin{array}{c}1994 \\
\text { May/June }\end{array}$ & $\begin{array}{c}1995 \\
\text { Grade } 4\end{array} \quad(\mathrm{n}=538)$ \\
\hline
\end{tabular}

Description of study cohort and timing of data collection.

As part of the evaluation of the impact of Coeur en santé St Louis du Parc, a school-based heart health promotion programme, we collected data on changes in smoking behaviour from year to year among young children attending inner-city elementary schools located in multiethnic, low-income neighbourhoods in Montreal, Canada. This report describes the one-year predictors of smoking initiation among never-smokers, as well as the one-year predictors of continued smoking among ever-smokers in this young population.

\section{Methods}

This study is a secondary analysis of data collected as part of Coeur en santé St Louis du Parc, a five-year, non-randomised, controlled trial to evaluate the impact of a school-based heart health promotion programme on children aged 9-12 years. For this trial, all eight elementary schools located in St Louis du Parc, a low-income, multiethnic, neighbourhood in central Montreal, were designated intervention schools. Two comparison schools were matched to each intervention school (for a total of 16 comparison schools) based on the mother tongue of students in the school as compiled by the Department of Intercultural Affairs of the Montreal Catholic School Commission, and a school-specific composite poverty index. ${ }^{21}$ Comparison schools were selected from among the remaining 327 elementary schools in Montreal.

Data to evaluate the impact of the Coeur en santé St Louis du Parc programme on student smoking, dietary, and physical activity behaviours were collected in surveys conducted in the classroom each May/June from 1993 to 1997, among all grade 4, 5, and 6 students (aged 9-12 years) for whom informed parental consent had been obtained, in the 24 study schools, including special education and learning impaired students. Over the five years of data collection, data were collected from a total of 11195 students- $80.9 \%$ of eligible students completed the in-class questionnaire (the proportion ranged from $75.0-83.8 \%$ over the five years); $3.5 \%$ (range $2.6-4.4 \%$ ) were absent on the day of questionnaire administration; and $15.6 \%$ (range $11.8-22.4 \%$ ) did not participate because their parents did not provide consent.

In 1993, data were also collected directly from parents in self-administered parent ques- tionnaires sent home with each student. Taking siblings into account, data were collected from mothers or fathers in $67.5 \%$ of families represented in the May/June 1993 database.

SUBJECTS

For the study reported here, we identified two sequential cohorts of grade 4 and 5 students aged 9-12 years with one-year follow-up data, from the first three years of data collected for the Coeur en santé St Louis du Parc project. None of the subjects included in this assessment had been exposed to the Coeur en santé St Louis du Parc programme. Specifically, one cohort consisted of students in grades 4 and 5 for whom we had data from May/June 1993 and one-year follow-up data from May/June 1994. The second cohort consisted of students in grades 4 and 5 for whom we had data from May/June 1994 and one-year follow-up data from May/June 1995 (figure 1). A total of 363 students were included in both cohorts because we had data for them for all three years (1993-1995). For these students, 1993 "baseline" data were used to predict smoking status in 1994, and 1994 "baseline" data were used to predict smoking status in 1995.

Of 2804 grade 4 and 5 students aged 9-12 years in the two cohorts at "baseline", one-year follow-up data were collected from 1873 subjects $(66.8 \%)$. Census data show that there is relatively high mobility among residents in $\mathrm{St}$ Louis du Parc. In 1991, 55\% reported that they had lived in a different dwelling five years previously, compared with $48 \%$ in Montreal. ${ }^{22}$

PROCEDURE

Data were collected at each data collection period in two visits to each school. During the first visit, anthropometric measures including height and weight were obtained by lay interviewers who had been trained according to a standardised protocol. ${ }^{23}$ In the May/June 1993 survey only, students were then given an envelope containing two questionnaires to be taken home and completed by their parents/caretakers, and returned to the classroom teacher. This questionnaire collected data on the sociodemographic characteristics and lifestyle behaviours of parents/caretakers.

During the second visit to each school, students completed a questionnaire administered by two interviewers in French or English according to the language of instruction in the school. Data collected in these student questionnaires, which took 30-45 minutes, included sociodemographic characteristics of the student (date of birth; gender; family composition; language(s) spoken; number of years lived in Canada; country(ies) of birth for the subject, mother, and father; and employment status of the mother and father), lifestyle behaviours (smoking status, level of physical activity, consumption of "junk food", sedentary behaviour), and finally, selected psychosocial characteristics related to these lifestyle behaviours. A detailed description of data collection procedures and study variables is available. ${ }^{24}{ }^{25}$ The following paragraphs provide details on selected study variables. 
MEASURES

An income sufficiency variable was created based on data collected in parents' questionnaires, by adjusting the total household income by the number of people in the household, and comparing this to the 1991 Canadian Census definitions of poverty. ${ }^{22}$ Subjects were categorised into high, sufficient, or insufficient household income.

Two variables were created to study the possible influence of cultural factors and ethnicity on smoking onset. First, "family origin" was attributed to each subject using an algorithm based on the country(ies) of birth for the mother, father, and student, and the language(s) spoken by the student. Family origins were grouped into categories based on language similarity or geographic proximity of the countries of birth, or both. Second, "per cent lifetime in Canada" was calculated as years lived in Canada divided by age (in years). Subjects were categorised into less than $25 \%$ of lifetime, 25-49\%, 50-74\%, 75-99\%, and $100 \%$. Children in the $100 \%$ category included those who had been born and had lived all their lives in Canada.

Student smoking status was measured in two items adapted from previous research ${ }^{26}$ : (a) Have you ever smoked a cigarette, even just a puff? Response categories included "No"; "Yes, 1 or 2 times"; "Yes, 3 to 10 times"; and "Yes, more than 10 times"; and (b) Check the one box below which describes you best. Response categories included: "You have never smoked"; "You have smoked, but not at all in the past year"; "You smoked once or a couple of times in the past year"; "You smoke a couple of times each month"; "You smoke a couple of times each week"; and "You smoke every day". Students were categorised as never-smokers if they reported no smoking at all. Ever-smokers included past smokers (those who had smoked but not at all in the past year) and current smokers. Current smokers included those trying smoking (those who had smoked once or twice in the past year), experimenters (students who had smoked three or more times in the past year, but did not smoke on a regular basis), and regular smokers (students who smoked a couple of times each month or each week and those who reported smoking every day). Smoking initiation was defined as movement from never-smoked at baseline to any level of smoking at the one-year follow up. ${ }^{27}$ "Continuing smokers" included ever-smokers at baseline who reported current smoking in the one-year follow up.

Data on the smoking behaviour of friends, siblings, and parents were obtained in the student questionnaires. Agreement between students' reports of parents' smoking status and parents' self-reports of smoking obtained in 1993 when parents completed a self-administered parent questionnaire, was excellent for mothers, and very good for fathers $\left(\kappa=0.82\right.$ and 0.72 , respectively). ${ }^{28}$ The Spearman rank correlation coefficient between mother who smokes and father who smokes was $0.30 ; p=0.0001$. Therefore, we created a single variable "mother and/or father who smokes" (yes, no) for analysis. Similarly, the correlation between brother and sister smoking was $r=0.17 ; \mathrm{p}=0.0001$. We created a single variable, "sibling(s) who smokes" (yes, no) for analysis. Body mass index (BMI) was computed by weight $(\mathrm{kg}) /$ height $(\mathrm{m}) .^{2}$ Students were categorised according to age-specific and gender-specific BMI percentiles obtained from the National Health and Nutrition Examination Survey II (NHANES II) conducted in the United States. ${ }^{29}$ "Not overweight" included students whose BMI was less than the 85th age-specific and gender-specific percentile. "Overweight" included students at or over the 85 th age-specific and gender-specific percentile. $^{30} 31$

Frequency of consumption of 10 high fat/“junk food” items/groupings was measured by the question: "During the past week from Monday to Sunday, how often did you eat the following foods ... hot dogs, hamburgers, fried chicken (Kentucky Fried Chicken), bacon or sausages, French fries/poutine, donuts/cakes/ pastries, candy/chocolate bars, soft drinks, ice cream, and potato chips/fritos/doritos." Responses to each item were scored 1 (every day, often, three or more times), 2 (once, a couple of times, once or twice), or 3 (never), and summed to create a "high fat/junk food score". The internal reliability coefficient (Cronbach's $\alpha$ ) of the score was 0.77 . Scores ranged from 10 to $30($ mean $=22.3($ SD 3.7) $)$, with lower scores indicating higher high-fat/ junk food consumption. Subjects were categorised into frequent (10-21), occasional (22-23), and infrequent (24-30) high fat/junk food consumption. In a previous validation study among 81 adult volunteers, the correlation between a similar "junk food" score and percentage total energy from saturated fat as measured in diet history, was $0.48 .^{32}$

\section{ANALYSIS}

Baseline or follow-up data on smoking status, or both, were missing for 49 of the 1873 subjects. Therefore, the analyses reported here are based on a total of 1824 subjects.

One-year predictors of smoking initiation among never-smokers at baseline were identified in multiple logistic regression analysis in which the dependent variable was never-smoked vs ever-smoked at one-year follow up. All students who reported ever smoking at baseline were excluded from these analyses. Potential predictors investigated included sociodemographic characteristics of students and their parents, lifestyle behaviours and BMI of the student, and smoking behaviours of family members and friends. Because of the large proportion of missing data for parents' education and for household income, these variables included a "missing" category. All exposures associated with the dependent variables in univariate analyses, were entered into the models concurrently. Only those significant at $p \leqslant 0.05$ in stepwise procedures were retained. Analyses were completed using the BMDP statistical package. ${ }^{33}$ Because both the univariate and multivariate analyses suggested that the 
Table 1 Comparison of selected characteristics of study subjects and children lost to follow up, Montreal, Canada, 1993-1995

\begin{tabular}{llll}
\hline & $\begin{array}{l}\text { Study subjects } \\
(n=1824)\end{array}$ & $\begin{array}{l}\text { Children lost to follow up } \\
(n=931)\end{array}$ & $p$ \\
\hline Male (\%) & 50.0 & 50.1 & 0.98 \\
Mean age (SD) (years) & $10.5(0.8)$ & $10.6(0.9)$ & 0.02 \\
Mean no (SD) persons/household & $4.6(1.5)$ & $4.6(1.7)$ & 0.90 \\
Two-parent family (\%) & 73.4 & 69.4 & 0.03 \\
Born in Canada (\%) & & & \\
Subject & 64.5 & 53.1 & 0.00 \\
Mother & 27.6 & 24.3 & 0.07 \\
Father & 23.3 & 22.1 & 0.49 \\
Family origin (\%) & & & \\
Europe & 22.5 & 18.8 & \\
Central America/Caribbean & 21.7 & 19.8 & \\
Canada & 20.8 & 19.5 & \\
Asia & 14.7 & 19.0 & \\
Arabic-speaking countries & 5.2 & 6.4 & 0.41 \\
South America & 4.6 & 4.5 & 0.00 \\
Other & 10.6 & 11.8 & 0.77 \\
Employed (\%) & & & \\
Father & 84.3 & 83.0 & 0.91 \\
Mother & 66.6 & 59.0 & 0.24 \\
Smoke (\%) & & & 0.40 \\
Subject & 21.1 & 20.6 & \\
Mother & 25.4 & 25.6 & \\
Father & 45.7 & 12.3 & \\
Sibling(s) & 10.8 & 27.6 & \\
Friends & 26.1 & & \\
& & & \\
\hline
\end{tabular}

predictors of smoking initiation did not differ by gender, these analyses combine boys and girls.

We also investigated predictors of continued smoking among the 229 boys and 156 girls who had ever smoked at baseline. The dependent variable was whether or not the subject was a current smoker at the one-year follow up. All subjects who were never-smokers at baseline were excluded from these analyses. In addition to the variables investigated as potential predictors of smoking initiation described above, we also investigated baseline smoking status as a potential independent predictor in these models. Both the univariate and multivariate analyses suggested that the predictors of continued smoking differed by gender. Therefore, these analyses are presented separately for boys and girls.

Use of the odds ratio as the parameter of interest in a prospective longitudinal study is somewhat controversial, ${ }^{34}$ in part because it could overestimate the relative risk if the outcome studied is not rare. However, because the outcome of interest in this study was binary, because risk estimates and odds estimates are mathematically co-dependent, and because of its common usage and ease of interpretation, we report here the odds ratio.

\section{Results}

Table 1 shows the sociodemographic characteristics of study subjects and highlights their ethnic diversity. A total of 104 countries of birth were reported by subjects for themselves and their parents. Almost half of the fathers $(45.7 \%)$ and $25.4 \%$ of the mothers smoked. Children lost to follow up differed from those who remained in the study in several respects: they were slightly older, fewer lived in two-parent families, fewer were born in Canada, and fewer mothers were employed (table 1).

PATTERNS OF SMOKING ONSET

At baseline, 17.1\% (95\% confidence interval $(\mathrm{CI}))=16.7$ to 19.2$)$ of girls and $25.1 \%(95 \%$ $\mathrm{CI}=22.3$ to 27.9$)$ of boys had ever smoked; $15.5 \%(95 \% \mathrm{CI}=13.8$ to 17.2$)$ of all children were past smokers, $3.1 \%(95 \% \mathrm{CI}=2.3$ to 3.9) were currently trying smoking, and $2.6 \%$ $(95 \%$ CI $=1.9$ to 3.3$)$ were experimental/ regular smokers. A year later, $25.7 \%$ of girls (95\% CI $=22.8$ to 28.5 ) and $34.6 \%$ of boys $(95 \% \mathrm{CI}=31.6$ to 37.7$)$ had ever smoked; $19.1 \%$ of all children ( $95 \% \mathrm{CI}=17.3$ to 20.9$)$ were past smokers, $4.5 \%(95 \% \mathrm{CI}=3.6$ to 5.5) were trying, and $6.5 \%(95 \% \mathrm{CI}=5.4$ to 7.6) were experimental/regular smokers. Although a lower proportion of girls had ever smoked at baseline, the patterns of change over a year were similar among boys and girls.

Baseline smoking status was predictive of smoking status a year later (table 2). Most never-smokers $(82.4 \%)$ remained neversmokers. Of particular interest, $50.0 \%$ of children trying smoking at baseline did not progress, while $50.0 \%$ continued to try or progressed to experimental/regular smoking. Also, there was a marked pattern of progression to experimental/regular smoking by past smoking experience. Only $2.6 \%$ of never-smokers reported regular/experimental smoking a year later; $16.3 \%$ of past smokers, $32.1 \%$ of those trying, and $38.3 \%$ of experimental/regular smokers at baseline reported experimental/ regular smoking a year later. The patterns of progression were similar among boys and girls.

It is notable that the data in table 2 are reported exactly as the children responded in the questionnaires, and therefore provide information on misclassification related to selfreports of smoking status among young children. Of particular interest, 88 of 385 eversmokers at baseline $(22.8 \%)$, reported never having smoked in the one-year follow up. These subjects are misclassified either at baseline (that is, they reported having smoked at baseline when in fact they had never smoked) or at the one-year follow up (they had "forgotten" about earlier smoking experiences that they had correctly reported a year earlier). Comparison of the characteristics of these

Table 2 Smoking status at one-year follow up according to baseline smoking status among elementary schoolchildren in multiethnic, low-income, inner-city neighbourhoods, Montreal, Canada, 1993-1995 ( $n=1824)$

\begin{tabular}{|c|c|c|c|c|c|c|c|c|c|}
\hline \multirow[b]{3}{*}{ Baseline smoking status } & \multirow[b]{3}{*}{ Total $n$} & \multicolumn{8}{|c|}{ Follow-up smoking status } \\
\hline & & \multicolumn{2}{|c|}{ Never smoked } & \multicolumn{2}{|c|}{ Past smoker } & \multicolumn{2}{|c|}{ Currently trying } & \multicolumn{2}{|c|}{ Currently experimental/ regular } \\
\hline & & $\%$ & $95 \% C I$ & $\%$ & $95 \% C I$ & $\%$ & $95 \% C I$ & $\%$ & $95 \% C I$ \\
\hline Never smoked & 1439 & 82.4 & $80.4-84.4$ & 12.1 & $10.4-13.8$ & 2.9 & $2.0-3.8$ & 2.6 & $1.7-3.4$ \\
\hline Past smoker & 282 & 25.2 & $20.1-30.2$ & 49.3 & $43.5-55.1$ & 9.2 & $5.8-12.6$ & 16.3 & $12.0-20.6$ \\
\hline Currently trying & 56 & 10.7 & $2.6-18.8$ & 39.3 & $26.5-52.1$ & 17.9 & $10.9-27.9$ & 32.1 & $19.9-44.4$ \\
\hline Currently experimental/regular & 47 & 23.4 & $11.3-35.5$ & 29.8 & $16.7-42.9$ & 8.5 & $0.5-16.5$ & 38.3 & $24.4-52.2$ \\
\hline
\end{tabular}

$\mathrm{CI}=$ confidence interval. 
Table 3 Univariate associations between selected variables and smoking initiation and continuation among elementary schoolchildren in multiethnic, low-income, inner-city neighbourhoods, Montreal, Canada, 1993-1995

\begin{tabular}{|c|c|c|c|c|c|c|}
\hline & \multirow{2}{*}{\multicolumn{2}{|c|}{$\begin{array}{l}\text { Initiationt } \\
(n=1439)\end{array}$}} & \multicolumn{4}{|c|}{ Continued smoking $\neq$} \\
\hline & & & \multicolumn{2}{|c|}{ Boys $(n=229)$} & \multicolumn{2}{|c|}{ Girls $(n=156)$} \\
\hline & $n^{\star}$ & $\%$ & $n^{\star}$ & $\%$ & $n^{*}$ & $\%$ \\
\hline Age (years) & & & & & & \\
\hline 9 & 173 & 9.3 & 21 & 14.3 & 15 & 26.7 \\
\hline 10 & 595 & 14.4 & 69 & 23.2 & 61 & 21.3 \\
\hline 11 & 535 & 20.7 & 99 & 36.4 & 59 & 45.8 \\
\hline 12 & 133 & 30.1 & 39 & 43.6 & 20 & 30.0 \\
\hline Gender & & & & & & \\
\hline Male & 683 & 20.8 & 229 & 31.4 & ND & ND \\
\hline Female & 756 & 14.7 & ND & ND & 156 & 32.0 \\
\hline Grade & & & & & & \\
\hline 4 & 728 & 14.6 & 96 & 20.8 & 61 & 14.7 \\
\hline 5 & 711 & 20.7 & 133 & 39.1 & 95 & 43.2 \\
\hline Family status & & & & & & \\
\hline Two-parent & 1071 & 16.8 & 168 & 35.7 & 100 & 32.0 \\
\hline Single-parent/other & 368 & 19.8 & 61 & 19.7 & 56 & 32.1 \\
\hline Family origin & & & & & & \\
\hline Canada & 276 & 23.2 & 53 & 34.0 & 43 & 39.5 \\
\hline Europe & 302 & 18.2 & 59 & 33.9 & 41 & 31.7 \\
\hline Central America/Caribbean & 321 & 14.0 & 33 & 33.3 & 33 & 30.3 \\
\hline Other & 511 & 16.6 & 79 & 27.8 & 36 & 27.8 \\
\hline$\%$ Lifetime in Canada & & & & & & \\
\hline$<100$ & 447 & 17.2 & 72 & 31.9 & 38 & 28.9 \\
\hline 100 & 856 & 17.9 & 141 & 32.6 & 105 & 36.2 \\
\hline Income sufficiency & & & & & & \\
\hline Insufficient & 260 & 18.8 & 37 & 29.7 & 28 & 39.3 \\
\hline Sufficient/high & 159 & 16.3 & 23 & 34.8 & 24 & 25.0 \\
\hline Missing & 1020 & 17.4 & 169 & 31.4 & 104 & 31.7 \\
\hline Mother's education & & & & & & \\
\hline Secondary or less & 336 & 20.5 & 46 & 28.3 & 39 & 25.6 \\
\hline More than secondary & 187 & 13.4 & 23 & 34.8 & 24 & 41.7 \\
\hline Missing & 916 & 17.4 & 160 & 31.9 & 93 & 32.3 \\
\hline Father's education & & & & & & \\
\hline Secondary or less & 230 & 22.6 & 33 & 39.4 & 16 & 25.0 \\
\hline More than secondary & 159 & 11.3 & 18 & 27.8 & 19 & 21.0 \\
\hline Missing & 1050 & 17.4 & 178 & 30.3 & 121 & 34.7 \\
\hline Father employed & & & & & & \\
\hline Yes & 1085 & 17.5 & 176 & 30.7 & 112 & 33.0 \\
\hline No & 210 & 16.2 & 22 & 36.4 & 23 & 26.1 \\
\hline Mother employed & & & & & & \\
\hline Yes & 893 & 18.0 & 150 & 31.3 & 102 & 33.3 \\
\hline No & 466 & 17.4 & 65 & 30.8 & 43 & 34.9 \\
\hline Baseline smoking status & & & & & & \\
\hline Past smoker & ND & ND & 168 & 25.6 & 114 & 25.4 \\
\hline Currently trying & ND & ND & 31 & 51.6 & 25 & 48.0 \\
\hline Currently experimental/regular & ND & ND & 30 & 43.3 & 17 & 52.9 \\
\hline Friends who smoke & & & & & & \\
\hline None/don't know & 1148 & 13.9 & 121 & 24.0 & 75 & 21.3 \\
\hline Few/most/all & 285 & 32.3 & 108 & 39.8 & 81 & 42.0 \\
\hline Mother who smokes & & & & & & \\
\hline No & 1096 & 15.8 & 151 & 30.5 & 91 & 33.0 \\
\hline Yes & 319 & 24.1 & 75 & 33.3 & 61 & 31.1 \\
\hline Father who smokes & & & & & & \\
\hline No & 783 & 12.6 & 90 & 30.0 & 67 & 34.3 \\
\hline Yes & 594 & 23.4 & 122 & 32.8 & 74 & 28.4 \\
\hline Brother(s) who smoke(s) & & & & & & \\
\hline No & 1365 & 17.3 & 195 & 28.7 & 129 & 31.0 \\
\hline Yes & 69 & 24.6 & 32 & 43.7 & 26 & 34.6 \\
\hline Sister(s) who smoke(s) & & & & & & \\
\hline No & 1387 & 16.9 & 208 & 28.8 & 128 & 31.2 \\
\hline Yes & 47 & 40.4 & 19 & 52.6 & 27 & 33.3 \\
\hline Mother encourages non-smoking & & & & & & \\
\hline No & 249 & 16.9 & 40 & 42.5 & 30 & 36.7 \\
\hline Yes & 1169 & 17.7 & 186 & 28.5 & 120 & 32.5 \\
\hline Father encourages non-smoking & & & & & & \\
\hline No & 443 & 17.4 & 75 & 37.3 & 51 & 27.4 \\
\hline Yes & 916 & 17.1 & 136 & 28.7 & 89 & 34.8 \\
\hline High fat/"junk food" consumption & & & & & & \\
\hline Frequent & 648 & 22.5 & 129 & 34.9 & 69 & 34.8 \\
\hline Occasional & 260 & 14.6 & 37 & 16.2 & 35 & 34.3 \\
\hline Infrequent & 362 & 14.4 & 34 & 35.3 & 35 & 28.6 \\
\hline Physical activity & & & & & & \\
\hline Infrequent & 535 & 14.0 & 57 & 28.1 & 66 & 31.8 \\
\hline Occasional & 316 & 15.8 & 35 & 22.9 & 26 & 26.9 \\
\hline Frequent & 588 & 21.8 & 137 & 35.0 & 64 & 34.4 \\
\hline Television programmes/day & & & & & & \\
\hline$\geqslant 6$ & 384 & 21.6 & 88 & 32.9 & 58 & 29.3 \\
\hline $4-5$ & 355 & 17.2 & 50 & 24.0 & 42 & 38.1 \\
\hline $2-3$ & 510 & 16.7 & 69 & 34.8 & 41 & 26.8 \\
\hline $0-1$ & 188 & 12.2 & 21 & 33.3 & 15 & 40.0 \\
\hline Overweight & & & & & & \\
\hline No & 860 & 18.9 & 144 & 33.3 & 82 & 21.9 \\
\hline Yes & 548 & 16.1 & 76 & 27.6 & 69 & 43.5 \\
\hline
\end{tabular}

*Totals for each potential predictor differ because of missing data (ND=no data). tIncludes never-smokers at baseline who moved to any level of smoking at one-year follow up. $\ddagger$ Includes ever-smokers at baseline who reported current smoking at one-year follow up.
Table 4 Independent predictors of smoking initiation among elementary schoolchildren in multiethnic, low-income, inner-city neighbourhoods, Montreal, Canada, $1993-1995(n=1224)$ *

\begin{tabular}{lll}
\hline Independent predictor & ORt & $95 \% C I$ \\
\hline Age & 1.6 & $1.3-2.0$ \\
Gender & ref. & \\
$\quad$ Female & 1.5 & $1.1-2.0$ \\
$\quad$ Male & & \\
Friends who smoke & ref. & \\
$\quad$ None/don't know & 2.3 & $1.7-3.3$ \\
$\quad$ Few/most/all & & \\
Sibling(s) who smoke & ref. & \\
$\quad$ No & 1.9 & $1.2-3.1$ \\
$\quad$ Yes & ref. & \\
Father/mother who smokes & 2.2 & $1.6-3.0$ \\
$\quad$ No & & \\
$\quad$ Yes & ref. & \\
High fat/“junk food” consumption & $1.1-2.1$ \\
$\quad$ Infrequent/occasional & 1.6 & $1.1-2.1$ \\
$\quad$ Frequent & & \\
\hline
\end{tabular}

^Excludes 215 subjects with missing data.

†Adjusted odds ratios (OR) and $95 \%$ confidence intervals ( $95 \% \mathrm{CI})$ obtained from multiple logistic regression analyses containing all independent predictors.

"misclassified" children with those of other ever-smokers, suggested that they were slightly younger and fewer were of Canadian family origin (data not shown). For the analyses reported here, these children are considered to have been ever-smokers at baseline who did not continue to smoke at the one-year follow up.

PREDICTORS OF SMOKING INITIATION

Over the one-year follow up, $14.7 \%$ of girls and $20.8 \%$ of boys who reported never smoking at baseline, initiated smoking. Table 3 shows the proportion of subjects who initiated smoking according to selected potential predictors. Table 4 shows that the independent predictors of initiation retained in the multivariate model included age, gender, friends who smoke, smoking by parents and siblings, and high fat/"junk food" consumption. None of the terms to test for interactions between each independent predictor and gender were significant, and an age $\times$ grade interaction term was not significant.

PREDICTORS OF CONTINUED SMOKING

At the one-year follow up, $32.0 \%$ of girls and $31.4 \%$ of boys who had ever smoked reported continued smoking. Table 5 shows that although age and friends who smoke were important predictors of continued smoking in both boys and girls, other predictors of continued smoking differed by gender. Boys who were current smokers at baseline were 2.6 times more likely to continue smoking than boys who were past smokers at baseline. In the model for girls, ever-smokers who were overweight were 3.5 times more likely to continue smoking than ever-smokers who were not overweight.

The variable "school" was included in the final models for smoking initiation and for continued smoking, to control for possible clustering related to homogeneity of students within schools. School was not significant in any model. Similarly, for the 363 students included in both the 1993 and 1994 cohorts, a variable to control for possible dependence 
Table 5 Independent predictors of continued smoking among elementary schoolchildren in multiethnic, low-income, inner-city neighbourhoods, Montreal, Canada, 1993-1995

\begin{tabular}{|c|c|c|c|c|}
\hline \multirow[b]{2}{*}{ Independent predictor } & \multicolumn{2}{|c|}{ Boys $(n=229)$} & \multicolumn{2}{|c|}{ Girls $(n=156)$} \\
\hline & $O R^{*}$ & $95 \% C I$ & $O R^{\star}$ & $95 \% C I$ \\
\hline Age & 1.7 & $1.2-2.4$ & 1.6 & $1.0-2.6$ \\
\hline \multicolumn{5}{|l|}{ Friends who smoke } \\
\hline None/don't know & ref. & & ref. & \\
\hline Few/most/all & 1.8 & $1.0-3.3$ & 2.7 & $1.2-5.7$ \\
\hline \multicolumn{5}{|l|}{ Overweight } \\
\hline No & ns & & ref. & \\
\hline Yes & & & 3.5 & $1.6-7.6$ \\
\hline \multicolumn{5}{|l|}{$\begin{array}{l}\text { Baseline smoking } \\
\text { status }\end{array}$} \\
\hline Past smoker & ref. & & ns & \\
\hline Current smoker & 2.6 & $1.4-5.0$ & & \\
\hline
\end{tabular}

*Adjusted odds ratios (OR) and 95\% confidence intervals $(95 \% \mathrm{CI})$ obtained from multiple logistic regression analyses containing all independent predictors. Confidence intervals sometimes include unity because of estimations in $p$ values and confidence intervals.

ns $=$ Not significant (factor did not meet the significance criterion of $p \leqslant 0.05)$.

between observations of the same subject, was not significant in any model. Finally, year of cohort (1993 or 1994) was not significant in the final models.

\section{Discussion}

This study is one of the first to examine the process of smoking onset longitudinally in young children in multiethnic, low-income, inner-city neighbourhoods. One of the more important findings is that one in six children aged 9-12 years who had never smoked, experimented with cigarettes over the one-year follow up. One in three children who had already tried smoking reported continued smoking. These data suggest that age 9-12 years is a critical period in the smoking onset process, at least in low-income, inner-city neighbourhoods, and that there is considerable need for prevention programmes for these age groups in these milieus.

Few studies have systematically differentiated predictors of smoking initiation from predictors of continued smoking among young children, from such a wide range of sociodemographic, anthropometric, behavioural, and psychosocial characteristics. Disentangling which factors are more important at each of these early stages of onset, could lead to more effective prevention programmes by identifying specific sub-groups to target with specific prevention messages. In particular, never-smokers and ever-smokers in this age range could be two distinct target groups, in need of different prevention programmes. Our results support the notion that, although age and smoking by friends are consistently important, the predictors of initiation and continuation do differ somewhat. Furthermore, there are important differences in the predictors of continued smoking between boys and girls. Programme planners will need to consider whether or not these differences warrant tailoring prevention programmes to specific subgroups.

There is considerable controversy over the relative contribution of parental, sibling, and peer smoking to the smoking onset process.
Many studies substantiate the strong influence of peer smoking ${ }^{155-44}$ evident as early as age 9. ${ }^{43}$ Parental smoking is thought to be a weak predictor of onset. ${ }^{6}$ It might lead children to try smoking, but be unrelated to smoking at a later age. ${ }^{43}$ Sibling smoking is positively associated with younger siblings beginning to smoke, and like parental smoking, might be more influential in the early stages of cigarette use. ${ }^{1}$ Family members and peers could exert influence in similar ways - through providing easy access to cigarettes, through communicating information about the physical and psychological effects of use, through modelling or demonstrating how to use cigarettes, and through conveying attitudes and social norms favourable to smoking. ${ }^{11}$ Peer and sibling smoking could also exert influence through the need for social acceptance from peers as well as through direct pressure to smoke. ${ }^{5}$

The results reported here substantiate the importance of peer smoking in both smoking initiation and continued smoking-neversmokers with friends who smoke were more than twice as likely as never-smokers without friends who smoke, to initiate smoking. Similarly, ever-smokers with friends who smoke were approximately twice as likely to continue smoking. Indeed, most psychosocial smoking prevention programmes focus on refusal skills training on the premise that such training will have a suppressive effect on onset by enabling non-using adolescents to refuse offers of cigarettes from peers. ${ }^{45}$

In addition, our results support previous findings that smoking by family members is a strong determinant of initiation, although it appears to be less important to continued smoking. In fact, the strength of the association between family members smoking and smoking initiation was similar to that of friends smoking. Although further research is needed to determine which aspects of sibling and parental use are most important in influencing children's smoking, ${ }^{11}$ this study provides compelling evidence for including elements to address familial influences in prevention programmes. More specifically, these results support the notion that it will not be sufficient to provide refusal skills training to children without taking the family environment into account. Intervention programmes must address the issue of exposure to smoking in the home. Minimally, prevention efforts should inform parents of the potential of their own smoking behaviour to influence the smoking behaviour of their offspring. More intense prevention efforts could include, in addition to parental education, cessation programmes for family members who smoke. Cessation programmes tailored to parents who smoke should emphasise the possible role modelling aspect of their behaviour, in smoking and possibly in their efforts to quit smoking.

A finding of considerable interest is that, whereas weight status was not associated with smoking initiation, overweight girls who had tried smoking were more than three times more likely to continue smoking than girls who were not overweight. Several studies have identified 
subgroups of "weight control smokers" among adult females, ${ }^{46-48}$ and there is evidence from both cross-sectional and longitudinal studies that adolescent girls use smoking for weight control. $^{49-51}$ The results reported here suggest that the association between smoking and weight status is evident even in pre-adolescent girls. Further research is needed to increase our understanding of how this association contributes to the smoking onset process in young girls, and whether or not smoking prevention programmes targeted at young girls should incorporate and emphasise healthy weight issues.

Interestingly, frequent consumption of high fat/"junk food" consumption was an independent predictor of smoking initiation, although it was unimportant to continued smoking in either boys or girls. This could indicate early clustering of unhealthy lifestyle behaviours.

Although there is considerable evidence of class-based differences in the prevalence of smoking, none of our indicators of social class including parents' education, household income, or parents' employment status, was associated with smoking onset. It is possible that missing data on parents' education and household income obscured the association. Alternatively, our results do support those of a recent longitudinal study of Danish children ${ }^{52}$, which found no associations between either household income or parents' education and later smoking as adults.

Finally, cultural factors and ethnicity were not important in this study. Some authors have argued that ethnic differences disappear once socioeconomic status is taken into account ${ }^{1}$. Our results support the notion that once familial and peer smoking are taken into account, cultural factors and ethnicity are not influential in the smoking onset process.

\section{LIMITATIONS}

Because the study schools do not represent a random sample of schools and because of possible selection bias caused by subjects lost to follow up, the generalisability of results might be limited. Also the number of potential predictors of smoking onset studied was restricted because of time limitations related to administration of the questionnaire in-class. Future research should examine whether other variables reported to be associated with smoking in young people ${ }^{111^{15-67}}$ are independent predictors of smoking initiation and continuation in this population.

Finally, this study did not use objective measures to validate self-reported smoking status of students. Nor did it use the bogus pipeline method which has been reported to enhance the validity of self-reports of smoking among the young. ${ }^{68}$ However biochemical measures are not perfect indicators of tobacco use and controversy exists over the efficacy of the pipeline method.$^{69}$ In addition the reliability of self-reports of smoking by adolescents has generally been quite high ( $88-100 \%)$, with most inconsistencies occurring among subjects who use tobacco infrequently. ${ }^{69}$
This research was conducted as part of the Projet québecois de démonstration en santé du coeur, which was financed by the National Health Research and Development Program, Health Canada (Grant No 66053754-H), the Quebec Ministry of Health and Social Services, and the Quebec Heart and Stroke Foundation. Jennifer O'Loughlin is a National Health Research Scholar. Lise Renaud is a Chercheur-boursier of the Conseil québecois de la recherche sociale. The authors gratefully acknowledge the contributions of Isabelle Rioux and Garbis Meshefedjian.

1 US Department of Health and Human Services. Preventing tobacco use among young people. A report of the Surgeon General, 1994. Atlanta, Georgia: Public Health Service, Centers for Disease Control and Prevention, Office on Smoking and Hist and Health, 1994. (US

2 Giovino GA, Henningfield JE, Tomar SL, et al. Epidemiology of tobacco use and dependence. Epidemiol Rev 1995;17:48-65.

3 Health Canada. Youth Smoking Survey: fact sheets. Ottawa, Canada: Minister of National Health and Welfare, 1996.

4 O'Malley PM, Johnston LD, Bachman JG. Adolescent substance use. Epidemiology and implications for public policy. Pediatr Clin North Am 1995;42:241-61.

5 Best JA, Thomson SJ, Santi SM, et al. Preventing cigarette smoking among school children. Ann Rev Public Health 1988;9:161-201.

6 Conrad KM, Flay BR, Hill D. Why children start smoking: predictors of onset. Br $\mathcal{F}$ Addict 1992;87:1711-24.

7 Glynn TJ, Anderson DM, Schwarz L. Tobacco-use reduction among high-risk youth: recommendations of a reduction among high-risk youth: recommendations of a 1991;20:279-91.

8 Glynn TJ. Improving the health of US children: the need for early interventions in tobacco use. Prev Med 1993;22:513-

9 Bush PJ, Iannotti RJ. Alcohol, cigarette, and marijuana use among fourth-grade urban schoolchildren in 1988/89 and 1990/91. Am F Public Health 1993;83:111-4.

10 Kelder SH, Perry CL, Klepp KI, et al. Longitudinal tracking of adolescent smoking, physical activity, and food choice behaviors. Am f Public Health 1994;84:1121-6.

11 Jackson C, Henriksen L, Dickinson D, et al. The early use of alcohol and tobacco: its relation to children's competence
and parent's behavior. Am 7 Public Health 1997;87:35964.

12 Stanton WR, Oei TPS, Silva PA. Sociodemographic characteristics of adolescent smokers. Int $\mathcal{F}$ Addict 1994;29:913 25.

13 Glendinning A, Shucksmith J, Hendry L. Social class and adolescent smoking behavior. Soc Sci Med 1994;38:1449 60.

14 Pierce JP, Fiore MC, Novotny TE, et al. Trends in cigarette smoking in the United States: educational differences are increasing. fAMA 1989;261:56-60.

15 Novotny TE, Warner KE, Kendrick JS et al. Smoking by blacks and whites: socioeconomic and demographic differblacks and whites: socioeconomic and demo

16 Winkleby MA, Jatulis DE, Frank E, et al. Socioeconomic status and health: how education, income, and occupation contribute to risk factors for cardiovascular disease. $\mathrm{Am} \mathcal{F}$ Public Health 1992:82:816-20.

17 US Department of Health and Human Services. The health benefits of smoking cessation. A report of the Surgeon General, 1990. Rockville, Maryland: Public Health Service, Centers for Disease Control, Office on Smoking and Health, 1990. (DHHS Publication No (CDC) 90-8416.)

18 Warburton DM, Revell AD, Thompson DH. Smokers of the future. Br F Addict 1991;86:621-5.

19 Chen VW. Smoking and the health gap in minorities. Ann Epidemiol 1993;3:159-64.

20 Kleinschmidt I, Hills M, Elliott P. Smoking behaviour can be predicted by neighbourhood deprivation measures. $\mathcal{F}$ Epidemiol Commun Health 1995;49:S72-7.

21 Conseil scolaire de l'île de Montréal. Classification des écoles primaires selon l'ordre décroissant de l'indice de défavorisation. Inscriptions au 30 septembre 1992. Montreal Island School Council. [Classification of primary schools in descending order, according to an indicator of deprivation. Enrollment to September 30, 1992.] Montreal, Canada: Conseil scolaire de l'île de Montréal.

22 Statistics Canada. Profile of census tracts in Montreal-Part B. Ottawa, Canada: Statistics Canada, 1994.

23 Evers SE, Hooper MD. Dietary intake and anthropometric status of 7 to 9 year old children in economically disadvanstatus of 7 to 9 year old children in economically disadvan14:595-603.

24 O'Loughlin J, Renaud L, Paradis G, et al. Prevalence and correlates of early smoking among elementary schoolchildren in multiethnic, low-income, inner-city neighborhoods. Ann Epidemiol 1998;8:308.

25 O'Loughlin J, Paradis G, Renaud L, et al. Prevalence and correlates of overweight among elementary schoolchildren in multiethnic, low income, inner-city neighborhoods in Montreal, Canada. Ann Epidemiol 1998. (In press)

26 Flynn BS, Worden JK, Secker-Walker RH, et al. Prevention of cigarette smoking through mass media intervention and
school programs. Am $\mathcal{F}$ Public Health 1992;82:827-33.

27 Santi S. Predictors of youth cessation. Literature Reviews Series No 4, Toronto, Canada: Ontario Tobacco Research Unit, 1995. 
28 Barnett T, O'Loughlin J, Paradis G, et al. Reliability of proxy reports of parental smoking by elementary schoolchildren. reports of parental smoking by

29 Frisancho AR. Anthropometric standards for the assessment of growth and nutritional status. Ann Arbor, Michigan: University of Michigan, 1990

30 Rolland-Cachera MF, Sempe M, Guilloud-Bataille M, et al. Adiposity indices in children. Am $\mathcal{F}$ Clin Nutr 1982; 36:178-84.

31 Spyckerelle Y, Gueguen RI, Guillemot M, et al. Adiposity indices and clinical opinion. Ann Hum Biol 1988;15:4554.

32 Gray-Donald K, O'Loughlin J, Richard L, et al. Validation of a short telephone-administered questionnaire to evaluate dietary interventions in low income communities in Montreal, Canada. I Epidemiol Commun Health 1997; 51:326-31.

33 BMDP statistical software manual. Los Angeles, California: BMDP Statistical Software, 1990.

34 Nurminen $M$. To use or not to use the odds ratio in epidemiologic analyses? Eur f Epidemiol 1995;11:365-71.

35 Landrine H, Richardson JL, Klonoff EA, et al. Cultural diversity in the predictors of adolescent cigarette smoking: the relative influence of peers. $\mathcal{F}$ Behav Med 1994;17:33146.

36 Swan AV, Creeser R, Murray M. When and why children first start to smoke. Int $\mathcal{F}$ Epidemiol 1990;19:323-30.

37 Zhu B, Liu M, Shelton D, et al. Cigarette smoking and its risk factors among elementary school students in Beijing. Am $\mathcal{F}$ Public Health 1996;86:368-75.

38 Cohen DA, Richardson J, LaBree L. Parenting behaviors and the onset of smoking and alcohol use: a longitudinal study. Pediatrics 1994;94:368-75.

39 Santi S, Best JA, Brown KS, et al. Social environment and smoking initiation. Int $\mathcal{F}$ Addict 1990-91;25:881-903.

40 Sasco AJ, Pobel D, Benhaim V, et al. Smoking habits in French adolescents. Rev Epidemiol Santé Publ 1993; 41:461-72.

41 Stanton WR, Lowe JB, Silva PA. Antecedents of vulnerability and resilience to smoking among adolescents. $f$ Adolesc ity and resilience to smo

42 Reimers TM, Pomrehn PR, Becker SL, et al. Risk factors for adolescent cigarette smoking. The Muscatine study. Am $\mathcal{F}$ Dis Child 1990;144:1265-72.

43 Botvin GJ, Epstein JA, Schinke SP, et al. Predictors of cigarette smoking among inner-city minority youth. If Der Behav Pediatr 1994;15:67-73.

44 Stanton WR, Silva PA. Children's exposure to smoking. Int fEpidemiol 1991;20:933-7.

45 Elder JP, Sallis JF, Woodruff SI, et al. Tobacco-refusal skills and tobacco use among high-risk adolescents. I Behav Med 1993;16:629-42.

46 Weekley III CK, Klesges RC, Reylea G. Smoking as a weight-control strategy and its relationship to smoking status. Addict Behav 1992;17:259-71.

47 Pomerleau C, Ehrlich E, Tate J, et al. The female weight-control smoker: a profile. $\mathcal{F}$ Substance Abuse 1993;5:391-400.

48 Clarke V, White V, Beckwith J, et al. Are attitudes towards smoking different for males and females? Tobacco Control smoking differen

49 French SA, Perry CL, Leon GR, et al. Weight concerns, dieting behavior, and smoking initiation among adolescents: a prospective study. Am F Public Health 1994 84: $1818-20$.
50 Halek C, Kerry S, Humphrey H, et al. Relationship between smoking, weight and attitudes to weight in adolescent smoking, weight and attitudes to weight
schoolgirls. Postgrad Med $\mathcal{F}$ 1993;69:100-6.

51 Camp DE, Klesges RC, Relyea G. The relationship between body weight concerns and adolescent smoking. Health Psychol 1993;12:24-32.

52 Osler M, Clausen J, Ibsen KK, et al. Maternal smoking during childhood and increased risk of smoking in young aldulthood. Int f Epidemiol 1995;24:710-4.

53 Mendis S. Tobacco use in a cohort of children in Sri Lanka. Br f Addict 1990;85:397-8.

54 Aitken PP, Eadie DR, Hastings GB, et al. Predisposing effects of cigarette advertising on children's intentions to smoke when older. Br f Addict 1991;86:383-90.

55 Santi SM, Cargo M, Brown KS, et al. Dispositional risk factors for smoking - stage transitions: a social influences program as an effect modifier. Addict Behav 1994;19:26985 .

56 Isohanni M, Moilanen I, Rantakallio P. Determinants of teenage smoking, with special reference to non-standard family background. Br f Addict 1991;86:391-8.

57 Bertrand LD, Abernathy TJ. Predicting cigarette smoking among adolescents using cross-sectional and longitudinal approaches. F Sch Health 1993;63:98-103.

58 Duncan TE, Tildesley E, Duncan SC, et al. The consistency substance use in adolescence. Addiction 1995;90:1647-60.

$59 \mathrm{McGee}$ R, Stanton WR. A longitudinal study of reasons for smoking in adolescence. Addiction 1993;88:265-71.

60 Wang MQI, Fitzhugh EC, Trucks J, et al. Physiological sensations of initial smoking in the development of regular smoking behavior. Percept Motor Skills 1995;80:1131-4.

61 Botvin GJ, Botvin EM, Baker E, et al. The false consensus effect: predicting adolescents' tobacco use from normative expectations. Psychol Rep 1992;70:171-8.

62 Bauman KE, Botvin GJ, Botvin EM, et al. Normative expectations and the behavior of significant others: an integration of traditions in research on adolescents' cigarette smoking. Psychol Rep 1992;71:568-70.

63 Sussman S, Hahn G, Dent CW, et al. Naturalistic observation of adolescent tobacco use. Int $\mathcal{F}$ Addict 1993;28:80311.

64 Sussman S, Brannon BR, Dent CW, et al. Relations of coping effort, coping strategies, perceived stress, and cigarette smoking among adolescents. Int f Addict 1994;28:599612

65 Vaidya SG, Naik UD, Vaidya JS. Effect of sports sponsorship by tobacco companies on children's experimentation with tobacco. BMF 1996;313:400-16.

66 While D, Kelly S, Huang W, et al. Cigarette advertising and onset of smoking in children: questionnaire survey. BMF 1996;313:398-9.

67 Gilpin EA, Pierce JP, Rosbrook B. Are adolescents receptive to current sales promotion practices of the tobacco industry? Prev Med 1997;26:14-21.

68 Evans RI, Hansen WB, Mittelmark MB. Increasing the validity of self-reports of smoking behavior in children. 7 validity of self-reports of smoking

69 Komro KA, Kelder SH, Perry CL, et al. Effects of a saliva pipeline procedure on adolescent self-reported smoking behavior and youth smoking prevention outcomes. Prev Med 1993;22:857-65. 